\title{
MOLECULAR ANALYSIS OF THE DENGUE VIRUS TYPE 1 AND 2 IN BRAZIL BASED ON SEQUENCES OF THE GENOMIC ENVELOPE-NONSTRUCTURAL PROTEIN 1 JUNCTION REGION
}

\author{
Cecília Luiza S. SANTOS(1), Maria Anice M. SALLUM(2), Peter G. FOSTER(3) \& Iray Maria ROCCO(1)
}

\begin{abstract}
SUMMARY
The genomic sequences of the Envelope-Non-Structural protein 1 junction region (E/NS1) of 84 DEN-1 and 22 DEN-2 isolates from Brazil were determined. Most of these strains were isolated in the period from 1995 to 2001 in endemic and regions of recent dengue transmission in São Paulo State. Sequence data for DEN-1 and DEN-2 utilized in phylogenetic and split decomposition analyses also include sequences deposited in GenBank from different regions of Brazil and of the world. Phylogenetic analyses were done using both maximum likelihood and Bayesian approaches. Results for both DEN-1 and DEN-2 data are ambiguous, and support for most tree bipartitions are generally poor, suggesting that E/NS1 region does not contain enough information for recovering phylogenetic relationships among DEN-1 and DEN-2 sequences used in this study. The network graph generated in the split decomposition analysis of DEN-1 does not show evidence of grouping sequences according to country, region and clades. While the network for DEN-2 also shows ambiguities among DEN-2 sequences, it suggests that Brazilian sequences may belong to distinct subtypes of genotype III.
\end{abstract}

KEYWORDS: Dengue1; Dengue2; E/NS1; Brazil; Phylogeny.

\section{INTRODUCTION}

Dengue is an acute febrile illness that threatens $2.5-3$ billion people living in tropical and subtropical regions of Africa, Asia and the Americas $^{12}$. The etiological agent is a single-stranded, positive-sense RNA virus, which comprises four genetically and antigenically distinct serotypes of the dengue virus (DEN-1 to DEN-4) of the family Flaviviridae, genus Flavivirus. The endemic cycle of DEN viruses involve human hosts and mainly the mosquito vector Aedes aegypti in most urban centers of the tropics ${ }^{10,11}$.

Infections by any of the four serotypes can result in a mild, selflimited illness, the dengue fever (DF) or a more severe form, the dengue hemorrhagic fever and dengue shock syndrome (DHF/DSS). Infection by one serotype does not protect against infection by a second serotype. In fact, secondary infection by a heterologous dengue serotype is considered the main risk factor associated to the occurrence of DHF/ $\mathrm{DSS}^{14}$. On the other hand, severe manifestation of the disease observed in primary infection suggests that viral factors might also be involved 9,28,30. However, the viral factors responsible for emergence of DHF/DSS are not well understood, mainly because of absence of in vivo and in vitro models to be used in laboratory studies.

In Brazil, dengue is of great concern. About 2,000,000 cases have been registered since its dramatic resurgence as epidemic of dengue fever in 1986, in an outbreak of DF caused by DEN-1 in Rio de Janeiro.
Dengue type 2 virus was isolated in this state in 1990 during an epidemic with several cases of DHF/DSS ${ }^{7}$. Serotype DEN-3, detected for the first time in 1999, was isolated from a patient who arrived from Nicaragua ${ }^{26}$ Autochthonous infections caused by DEN-3 were registered in Rio de Janeiro in January $2001^{22}$. After that it spread throughout Brazil, cocirculating with DEN-1 and DEN-2 in several communities, increasing the risk of emergence of DHF/DSS.

In São Paulo State, DEN-1 illness was first detected in 1987 in a focal outbreak in the municipalities of Guararapes and Araçatuba. In the summer of 1990-1991, a large epidemic started in Ribeirão Preto. It expanded rapidly to other regions and since then periodic dengue epidemics associated with periods of hyperendemicity have been occuring in São Paulo State. DEN-2 virus was identified in 1996 and autochthonous cases of DEN-3 were notified in 2002 (Centro de Vigilância Epidemiológica da Secretaria de Estado da Saúde de São Paulo).

Aedes aegypti was eliminated from Brazil after a successful yellow fever mosquito vector control in the beginning of the $20^{\text {th }}$ century. However, this species was reintroduced in 1967 and spread throughout the country. Nowadays Ae. aegypti infests more than two thirds of the municipalities in São Paulo State. Being the wealthiest state in Brazil, São Paulo is a commercial center, and has a lot of traffic in goods and people. It is well known that human travelers infected and incubating DEN virus can act as a reservoir and thus introduce new serotypes or variants in a country or region. Consequently, molecular epidemiologic

This work was supported by Secretaria de Estado da Saúde, São Paulo and Fundação de Amparo à Pesquisa do Estado de São Paulo (FAPESP), grant no. 99/00558-2.

(1) Serviço de Virologia, Instituto Adolfo Lutz, Av. Dr. Arnaldo 355, 01246-902 São Paulo, Brasil.

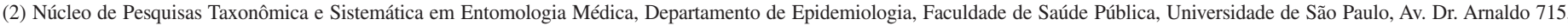
01246-904 São Paulo, Brasil.

(3) Department of Zoology, The Natural History Museum, Cromwell Road, SW75BD, London, UK.

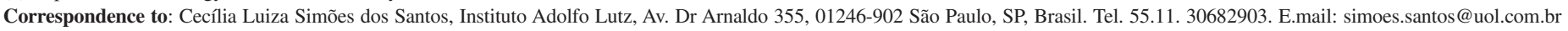
and csantos@ial.sp.gov.br 


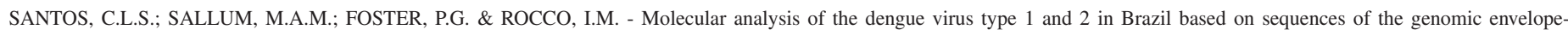
nonstructural protein 1 junction region. Rev. Inst. Med. trop. S. Paulo, 46(3):145-152, 2004.

studies are now stressed in order to monitor eventual appearance of genetic changes in dengue viruses, to identify which genotypes are circulating in an area, and to monitor introduction of new genotypes.

Genetic diversity of DEN-1 and DEN-2 viruses were addressed, based mainly on comparative sequence analyses that led to the recognition of several genotypes within each serotype. For DEN-1, three to five genotypes were proposed ${ }^{4,8,24}$ and for DEN-2 five genotypes were suggested ${ }^{19,24,25}$. In Brazil, the genetic diversity of DEN-1 has been poorly explored and consequently few strains have been characterized at the molecular level. In the present study, the genomic sequences of the Envelope-Nonstructural protein 1 (E/NS1) regions of $84 \mathrm{DEN}-1$ and 22 DEN-2 isolates from Brazil were determined. Most of these strains were isolated in the period from 1995 to 2001 in endemic and regions of recent dengue transmission in São Paulo State. In addition, representative sequences of genotypes I to $\mathrm{V}$ of DEN-1, and genotypes II and III of DEN-2 were included for comparison with Brazilian isolates. These sequences include both previously published sequences ${ }^{21,24,25}$ and sequences newly determined for this study. The main objectives of this study are: (1) to characterize the genotypes of DEN-1 and DEN-2 serotypes that are circulating in the State of São Paulo, (2) to identify potential origins of isolates, and (3) to examine phylogenetic relationships between sequences.

\section{MATERIALS AND METHODS}

Virus: All new DEN-1 and DEN-2 strains used in this study were isolated from the original patient serum between 1995-2001. Sera were collected from endemic areas in Araçatuba, São José do Rio Preto, Ribeirão Preto, and Barretos, and from regions of recent dengue transmission in Santos, Campinas, São Paulo, and Barueri. We also included DEN-1 isolates, which were obtained from reference center collection at the "Instituto Adolfo Lutz", São Paulo. These samples were obtained from patients during the first DEN-1 epidemic that occurred in Ribeirão Preto in 1990 and from patients who were infected in the states of Mato Grosso do Sul and Alagoas in 1991. All dengue virus isolates were from DF patients except for DEN-2 strain 190947, which was obtained from a DHF patient. All nucleotide sequences of E/NS1 gene junction region of DEN-1 and DEN-2 serotypes generated for this study are deposited in GenBank under accession numbers AY306015 to AY306098 (DEN-1), and AY306099 to AY306120 (DEN-2).

Viral isolation and serotype identification: Dengue viruses were isolated by inoculation of $20 \mu \mathrm{l}$ serum aliquot/tube in Aedes albopictus clone C6/36 cell culture. Serotype identification was achieved by indirect fluorescent antibody test using serotype-specific monoclonal antibodies according to GUBLER et al. ${ }^{13}$.

RNA extraction: Viral RNA was extracted from the culture supernatants of the first passage to C6/36 infected cells according to the procedure described by $\mathrm{CHOMCZYNSKI} \& \mathrm{SACCHI}^{3}$.

Amplification and sequencing of the E/NS1 gene junction: A region encompassing 240 nucleotides of the E/NS1 gene junction was amplified by RT-PCR with primers described by RICO-HESSE ${ }^{24}$. A single reaction tube procedure was performed with the "SuperScript ${ }^{\mathrm{TM}}$ One-Step RT-PCR with Platinium ${ }^{\mathrm{R}}$ Taq System" (Invitrogen/Life Technologies, CA, USA). The RT-PCR products were sequenced directly using the "ABI Prism ${ }^{\mathrm{R}}$ Big Dye ${ }^{\mathrm{M}}$ Terminator Cycle Sequencing Ready Reaction Kit" according to the manufacturer's protocol. Sequences were determined in an ABI sequencer model 377 (PE Applied Biosystems, Foster City, CA, USA).

Sequence alignment: Nucleotide sequences of the E/NS1 gene junction of DEN-1 and DEN-2 viruses were aligned separately using the multiple sequence alignment method as implemented in CLUSTALX $^{34}$.

Phylogenetic analysis: Isolates that exhibited identical sequences were excluded from all phylogenetic analyses. Serum strains, locations, years of isolation, code and GenBank accession numbers of the sequences utilized in the phylogenetic and split decomposition analyses are listed in Table 1 (DEN-1) and Table 2 (DEN-2). Maximum likelihood (ML) analyses were performed using PAUP $4.0 \mathrm{~b} 10^{31}$. The best model in PAUP was chosen using ModelTest 3.06 ${ }^{23}$. This program uses both a hierarchical likelihood ratio test (LRT) and the Akaike Information Criterion (AIC) to choose among available models; when the LRT and AIC disagreed the simpler model was chosen. After choosing a model in this way, the ModelTest tree was re-evaluated with a codon based site-specific (SS) model. Under the adopted model and using a NJ tree as the starting tree for branch-swapping, five iterative rounds of ML analysis were performed using the less intensive (NNI) to those using more intensive (TBR) branch-swapping. The most likely tree identified during each of these rounds was used as the starting tree for the next search, both for calculation of updated parameter values and for the initiation of branchswapping. Branch-swapping were respectively, Nearest Neighbor Interchange (NNI), Subtree Pruning Regrafting (SPR), and SPR, Tree Bisection Reconnection (TBR) and TBR. Bootstrapping used 100 pseudoreplicates, each using a search as described above except that the branch-swapping regime was shortened to NNI, a single SPR, and a single TBR. When using the SS model, the program P4 (available from PGF) was used to bootstrap the data, followed by use of PAUP to analyze the pseudoreplicates.

Bayesian inference of phylogeny was carried out using the computer program MrBayes $2.01^{16}$. Since the kinds of models available in this program have limited overlap with those in PAUP*, Bayesian analysis was carried out using GTR ${ }^{27}$ plus site-specific model. Program default values for prior probabilities were used. The Markov Chain Monte Carlo (MCMC) was allowed to run 5,000,000 generations for DEN-1, and $3,000,000$ generations for DEN-2 both sampled every 100 generations after a burn-in of 50,000 generations. Conflicting phylogenetic signals were examined using the Split Decomposition method ${ }^{2}$, which is developed in the program SplitsTree ${ }^{17}$. The maximum likelihood distance matrix between sequences was obtained using the $\mathrm{TrNef}+\Gamma \operatorname{model}^{33}$ for DEN-1 and GTR $+\Gamma \operatorname{model}^{27}$ for DEN-2 data.

\section{RESULTS}

Nucleotide and amino acid sequence analysis: Nucleotide sequences of the E/NS1 genome junction of 84 DEN-1 strains ( 77 samples isolated in São Paulo State between 1995-2001, four samples isolated in Ribeirão Preto, State of São Paulo in 1990, one from Mato Grosso do Sul and two from Alagoas in 1991) and 22 DEN-2 strains (isolated in São Paulo State between 1996-2001) were used to assess the degree of genetic diversity among Brazilian sequences. 


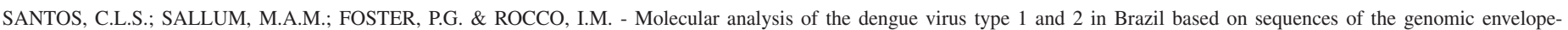
nonstructural protein 1 junction region. Rev. Inst. Med. trop. S. Paulo, 46(3):145-152, 2004.

Table 1

DEN-1 virus strains used in the phylogenetic and split decomposition analysis

\begin{tabular}{|c|c|c|c|c|}
\hline Strain & Code & Year of isolation & Location & GenBank acc.\# \\
\hline SPH $158985(\mathrm{~A})^{*}$ & SP95A & 1995 & Araçatuba, São Paulo / Brazil & AY306015 \\
\hline SPH 184232(B) & SP99B & 1999 & Santos, São Paulo / Brazil & AY306066 \\
\hline SPH 184477(C) & SP99C & 1999 & São José do Rio Preto, São Paulo / Brazil & AY306035 \\
\hline SPH 189720(D) & SP00D & 2000 & Ribeirão Preto, São Paulo / Brazil & AY306058 \\
\hline SPH 194573(E) & SP01E & 2001 & Barretos, São Paulo / Brazil & AY306075 \\
\hline SPH 182491(F) & SP98F & 1998 & Ribeirão Preto, São Paulo / Brazil & AY306054 \\
\hline SPH 197221(G) & SP01G & 2001 & Barueri, São Paulo / Brazil & AY306093 \\
\hline SPH 198979(H) & SP01H & 2001 & São Paulo, São Paulo / Brazil & AY306088 \\
\hline SPH 197357(I) & SP01I & 2001 & Barueri, São Paulo /Brazil & AY306097 \\
\hline SPH 159181(J) & SP95J & 1995 & Ribeirão Preto, São Paulo / Brazil & AY306049 \\
\hline SPH $167911(K)$ & SP97K & 1997 & Ribeirão Preto, São Paulo / Brazil & AY306053 \\
\hline SPH 191091(L) & SP00L & 2000 & Campinas, São Paulo / Brazil & AY306074 \\
\hline SPH 184069(M) & SP98M & 1998 & São José do Rio Preto, São Paulo / Brazil & AY306033 \\
\hline SPH 167148(N) & SP97N & 1997 & São José do Rio Preto, São Paulo / Brazil & AY306032 \\
\hline SPH 190477(O) & SP00O & 2000 & Campinas, São Paulo / Brazil & AY306073 \\
\hline SPH 202241(P) & SP01P & 2001 & São Paulo, São Paulo / Brazil & AY306091 \\
\hline SPH 194579(Q) & SP01Q & 2001 & Barretos, São Paulo / Brazil & AY306077 \\
\hline SPH $197218(\mathrm{R})$ & SP01R & 2001 & Barueri, São Paulo / Brazil & AY306092 \\
\hline SPH 117252(S) & SP90S & 1990 & Ribeirão Preto, São Paulo / Brazil & AY306040 \\
\hline SPH 194757 & Brd1SP & 2001 & Barretos, São Paulo / Brazil & AF520798 \\
\hline Mochizuki & Japan43 & 1943 & Nagasaki / Japan & M32929 \\
\hline IBH28326 & Nige68 & 1968 & Nigeria & M32927 \\
\hline 691475 & SriL69 & 1969 & Sri Lanka & M32913 \\
\hline 228682 & Phil74 & 1974 & Manila / Philippines & M32919 \\
\hline 228686 & Burm76 & 1976 & Burma & M32920 \\
\hline IBH13689 & Nige78 & 1978 & Nigeria & M32928 \\
\hline DAK29177 & Sene79 & 1979 & Bandia / Senegal & M32909 \\
\hline 1351 & Colo82 & 1982 & Colombia & M32900 \\
\hline 1378 & Mexi83 & 1983 & Mexico & M32901 \\
\hline ArA 15120 & Ivor85 & 1985 & Ivory Coast & M32922 \\
\hline CEA147 & Braz86 & 1986 & Ceará / Brazil & M32923 \\
\hline 391094 & Colo87 & 1987 & Guaviare / Colombia & M32911 \\
\hline 766602 & Taiw87 & 1987 & Kaohsiung / Taiwan & M32915 \\
\hline 28973 & Braz88 & 1988 & Brazil & M32908 \\
\hline 36589 & Ango88 & 1988 & Angola & M32912 \\
\hline
\end{tabular}

* Representative sequence variants detected in this study are shown between brackets

The nucleotide alignments of E/NS1 sequences of DEN-1 and DEN2 isolates indicate the presence of $19 \mathrm{DEN}-1$ and seven DEN-2 sequence variants, which were arbitrarily designated by letters: A to $\mathrm{S}$ for DEN-1 (Table 1), and A to $\mathrm{G}$ for DEN-2 (Table 2). These variants are not specific for a particular geographic region (Table 3 ). In addition, they are characterized by base substitutions that occur mainly in the third codon position and yield silent mutations; some of them are unique to an individual strain, whereas other base substitutions are shared by several dengue isolates. Comparison of the deduced amino acid sequences encoded in the E/NS1 region of DEN-1 and DEN-2 strains from Brazil included in this study reveals that amino acid sequence similarities range from 97.5 to $100.0 \%$ for dengue virus serotype 1 and 90.0 to $100.0 \%$ for dengue virus serotype 2 (MEGALIGN, DNASTAR, Inc.).

The E/NS1 alignment for 35 sequences of DEN-1 utilized in both phylogenetic and split decomposition analyses consists of 240 positions of which 65 are variable and 28 are parsimony-informative. For 29 sequences of DEN-2, the alignment generated 240 sites of which 59 are variable and 28 are parsimony-informative. Uncorrected ("p") distance between DEN-1 sequences ranged from 0\% between Brd1SP and SP01P strains to $11.25 \%$ between Taiw87 and SriL69, and Japan43 and SriL69; for DEN-2 sequences uncorrected ("p") distances ranged from $0 \%$ between ES95 and SP97A, BR90_1 and BR90_2, and RJ90_3 and RJ90_4 strains to $10.41 \%$ between Thai64 and RJ98 strains. Nucleotide frequencies of E/NS1 region for DEN-1 data are: $29.01 \%$ of A, $19.92 \%$ of $\mathrm{C}, 26.04 \%$ of $\mathrm{G}$ and $25.01 \%$ of $\mathrm{T}$, and DEN-2 are: $30.27 \%$ of $\mathrm{A}$, $19.28 \%$ of C, $25.67 \%$ of $\mathrm{G}$ and $24.77 \%$ of T. The standard $\chi^{2}$ test for base homogeneity implemented in PAUP $4.0 \mathrm{~b} 10^{31}$ was unable to reject homogeneity of base frequencies among either DEN-1 or DEN-2 sequences, either using all sites or just using variable sites $(p=1.000000)$.

\section{Phylogenetic and Split Decomposition analyses}

Dengue $1 \mathrm{E} / \mathrm{NS} 1$ gene region: ModelTest $3.06^{23}$ was used to choose a model. This program uses both a hierarchical likelihood ratio test (LRT) and the AIC to choose among available models in PAUP. The LRT 


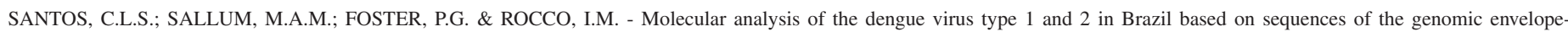
nonstructural protein 1 junction region. Rev. Inst. Med. trop. S. Paulo, 46(3):145-152, 2004.

Table 2

DEN-2 virus strains used in the phylogenetic and split decomposition analysis

\begin{tabular}{|c|c|c|c|c|}
\hline Strain & Code & Year of isolation & Location & GenBank acc.\# \\
\hline SPH $167231(\mathrm{~A})^{*}$ & SP97A & 1997 & São José do Rio Preto, São Paulo / Brazil & AY306099 \\
\hline SPH 173072 (B) & SP98B & 1998 & Ribeirão Preto, São Paulo / Brazil & AY306107 \\
\hline SPH 194766 (C) & SP01C & 2001 & Barretos, São Paulo / Brazil & AY306115 \\
\hline SPH 196706 (D) & SP01D & 2001 & Santos, São Paulo / Brazil & AY306111 \\
\hline SPH 183966 (E) & SP98E & 1998 & Santos, São Paulo / Brazil & AY306109 \\
\hline SPH $190947(\mathrm{~F})$ & SP00F & 2000 & Campinas, São Paulo / Brazil & AY306114 \\
\hline SPH $182452(\mathrm{G})$ & SP98G & 1998 & Ribeirão Preto, São Paulo / Brazil & AY306108 \\
\hline SPH 194757 & Brd2SP & 2001 & Barretos, São Paulo / Brazil & AF520799 \\
\hline 39056BR90 & BR90_1 & 1990 & Rio de Janeiro / Brazil & U91859 \\
\hline 40247BR90 & BR90_2 & 1990 & Rio de Janeiro / Brazil & U91861 \\
\hline BR39122RJ90 & RJ90_3 & 1990 & Rio de Janeiro / Brazil & AF529064 \\
\hline BR39325RJ90 & RJ90_4 & 1990 & Rio de Janeiro / Brazil & AF529065 \\
\hline BR51502BA95 & BA95_1 & 1995 & Bahia / Brazil & AF529066 \\
\hline BR52582ES95 & ES95 & 1995 & Espírito Santo / Brazil & AF529068 \\
\hline BR51504BA95 & BA95_2 & 1995 & Bahia / Brazil & AF529067 \\
\hline BR62515RJ98 & RJ98 & 1998 & Rio de Janeiro / Brazil & AF529072 \\
\hline BR61654RN98 & RN98_1 & 1998 & Rio Grande do Norte / Brazil & AF529071 \\
\hline BR64020RN98 & RN98_2 & 1998 & Rio Grande do Norte / Brazil & AF529073 \\
\hline BR64905RJ99 & RJ99 & 1999 & Rio de Janeiro / Brazil & AF529075 \\
\hline BR66985RJ00 & RJ00 & 2000 & Rio de Janeiro / Brazil & AF529078 \\
\hline BR66703ES00 & ESO0_1 & 2000 & Espírito Santo / Brazil & AF529076 \\
\hline BR66718ES00 & ESO0_2 & 2000 & Espírito Santo / Brazil & AF529077 \\
\hline 16681 & Thai64 & 1964 & Thailand & M32941 \\
\hline 8110827 & Jamaica81 & 1981 & Jamaica & M32950 \\
\hline 516 & Thai83 & 1983 & Thailand & M32947 \\
\hline 766635 & Taiw87 & 1987 & Kaohsiung / Taiwan & M32949 \\
\hline $57 \mathrm{~S}$ & Viet87 & 1987 & Saigon / Vietnam & M32948 \\
\hline 028 & Phil88 & 1988 & Manila / Philippines & M32932 \\
\hline K0074 & Thai94 & 1994 & Thailand & U87349 \\
\hline
\end{tabular}

*Representative sequence variants detected in this study are shown between brackets

Table 3

DEN-1 and DEN-2 sequence variants recovered from autochthones cases of dengue viruses infection detected in the geographic regions of the study

\begin{tabular}{lll}
\hline Locality & \multicolumn{2}{c}{ Serotype } \\
& DEN-1 & DEN-2 \\
\cline { 2 - 3 } & Variant & Variant \\
\hline Araçatuba/São Paulo State & A; C & not present \\
Barueri/São Paulo State & A; G; I; R & not present \\
Barretos/São Paulo State & E; P; Q & C \\
Campinas/São Paulo State & A; L; O & A; F \\
Ribeirão Preto/São Paulo State & A; D; F; J; K; S & B; G \\
Santos/São Paulo State & A; B; C & D; E \\
São José do Rio Preto/São Paulo State A; C; D; M; N & A; B \\
São Paulo / São Paulo State & A; B; H; P & not present \\
Mato Grosso do Sul State & A & not studied \\
Alagoas State & A & not studied \\
\hline
\end{tabular}

indicated the TrNef $+\Gamma$ model $^{33}$, while the AIC indicated the SYM $+\Gamma$ model ${ }^{40}$; the TrNef $+\Gamma$ model was chosen, it being the simpler of the two. Having chosen TrNef as the rate matrix, we looked at whether a codon based site specific (SS) among site rate variation could model the data better than the gamma model indicated by ModelTest. The NJ tree used by ModelTest was evaluated with the TrNef + SS model and gave an increase in log likelihood of 23.7 relative to the TrNef $+\Gamma$ model, at cost of 1 parameter, and so the TrNef + SS model was chosen as the best-fit model for DEN-1 data.

Maximum likelihood analysis was carried out under $\operatorname{TrNef}+\Gamma$ and TrNef + SS models. A single ML topology was generated under TrNef + $\Gamma$ model with a log likelihood of -897.38601 . Similarly, a single most likely tree with a log likelihood of - 873.75807 was generated under TrNef + SS model. These two topologies are identical and define a major clade, which includes six Brazilian sequences (Braz86, Braz88, Brd1SP, SP01H, SP01P and SP01R), five strains from Africa, five strains from Asia and three strains from Latin America. Within this major clade, Braz86 and Braz88 formed a subgroup with Taiw87, Phil74 and Japan43, whereas the position of Brd1SP, SP01H and SP01P was unresolved (Fig. 1). Phylogenetic relationships among the remaining DEN-1 sequences from the São Paulo State are unresolved (Fig. 1). ML bootstrap analysis under either TrNef $+\Gamma$ (not shown) or TrNef + SS models provides generally very poor support for relationships among DEN-1 sequences, with only six clades achieving $\geq 50 \%$ bootstrap proportions (Fig. 1). Bayesian $50 \%$ majority rule consensus tree (not shown) is similar to ML topology generated under both $\mathrm{TrNef}+\Gamma$ and $\mathrm{TrNef}+\mathrm{SS}$ models except for the placement of Braz88, which was recovered in a basal position within the clade consisting of Burm76, Colo87, Braz86, Taiw87, Phil74 and Japan43. 
In ML tree, Braz88 was placed within the clade consisting of Braz86, Taiw87, Phil74 and Japan43. In addition, SirL69 was recovered as sister to Ivor85, whereas Sene79 appeared as outgroup to (Ivor85, SriL69), and SP01H strain shared a sister-group relationship with Mexi83. Posterior probability for relationships among DEN-1 sequences are generally higher than ML bootstrap values, however, relationships among most sequences is poorly supported (Fig. 1). The network diagram generated with SplitTest ${ }^{17}$ using the maximum likelihood distance matrix recovered under the TrNef $+\Gamma$ model shows that all the sequences branched off separately from Nige68 except for (Taiw87, Phil74, Japan73), (SP99C, SP00O), (Sene79, SirL69) and (Brd1SP, SP01P), which cluster together having arisen from Nige68 (Fig. 2). This network does not show any evidence of grouping sequences according to country, region and date. Excluding Burm76, Ango88, Ivor85, Sene79, Nige68, SriL69, Nige78, Taiw87, Phil74 and Japan43 from the split decomposition analysis, it was possible to visualize two well-separated groups (not shown). The first group consists of six Brazilian sequences and three Caribbean strains of the genotype I. Although the relation among these sequences has some degree of ambiguity, it is reasonable to consider that they arose from Mexi83 sequence. In addition, the second group consists of several sequences isolated from the State of São Paulo, which may belong to a single outbreak.

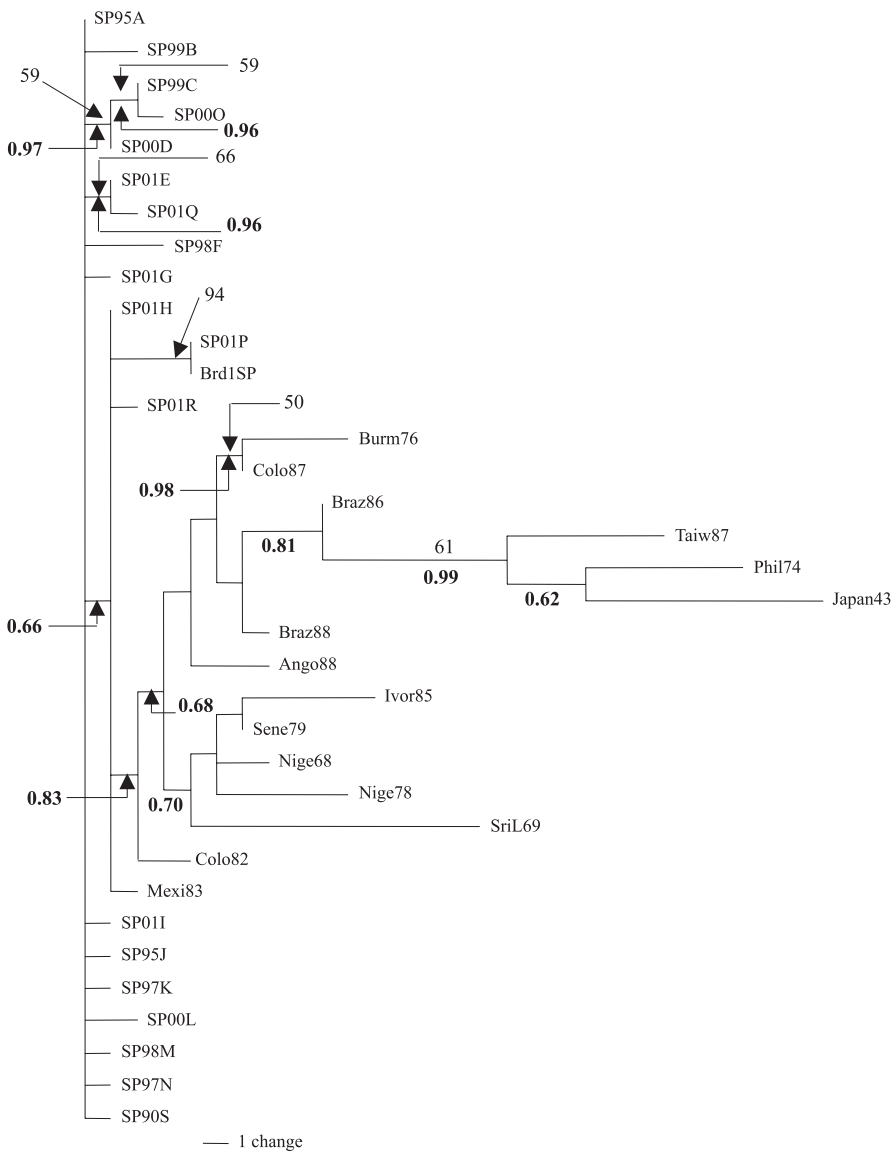

Fig. 1 - The single tree identified by maximum likelihood analysis of the E/NS1 junction region for DEN-1 data under the TrNef + SS model of nucleotide substitution. Numbers above branches indicate ML bootstrap proportions obtained under TrNef + SS model, and numbers below branches indicate posterior probabilities obtained under the GTR + SS model.
Dengue 2 E/NS1 gene region: The NJ tree was evaluated in the program ModelTest 3.06 ${ }^{23}$. The likelihood ratio test found the $\mathrm{K} 80+\Gamma$ model ${ }^{18}$ and the AIC found the GTR $+\Gamma$ model $^{27}$ to be the best-fit models for DEN-2 data. The simpler of the two, the $\mathrm{K} 80+\Gamma$ model, was chosen. Again, SS among site rate variation was tested by comparing the $\mathrm{K} 80+$ $\Gamma$ to the $\mathrm{K} 80+\mathrm{SS}$ models. The SS model gave an increase in log likelihood of 13.5 with one additional parameter, indicating that the SS model has a better fit to the data.

Maximum likelihood analysis was performed under $\mathrm{K} 80+\Gamma$ and $\mathrm{K} 80+$ SS. A single most likely tree with a log likelihood $=-786.88522$ was generated under the K80 $+\Gamma$ model. An identical ML topology was found under the $\mathrm{K} 80+$ SS model with $\log$ likelihood $=-773.37693$ (Fig. 3 ). The majority of DEN-2 sequences were recovered within a main clade, consisting of 16 Brazilian sequences, six Asian sequences and Jamaica81 sequence. Three subgroups were recovered within this clade: a basal subgroup consisting of RN98_1, which shares a sister-group relationship with RJ98; a clade leading to six Asian strains, Jamaica81, and four Brazilian strains; and a clade consisting of 10 Brazilian strains, which includes isolates from the states of São Paulo, Espírito Santo, Rio de Janeiro, Rio Grande do Norte and Bahia. In addition, two Brazilian sequences designated as BR90_2 and BR90_1 share a sister-group relationship with Jamaica81. Six sequences (four from São Paulo, one each from Bahia and Espírito Santo) clustered outside the large clade. Maximum likelihood bootstrap support for the majority of relationships among DEN-2 E/NS1 sequences is very poor with only eight groups achieving $>50 \%$ bootstrap proportion. The grouping leading to Asian strains except Viet 87 is moderately well supported ( $82 \%$ bootstrap value) (Fig. 3). Similarly, the sister-group relationships between Brazilian strains (BR90_2 and BR90_1) and Jamaica81 are supported by 82\% bootstrap

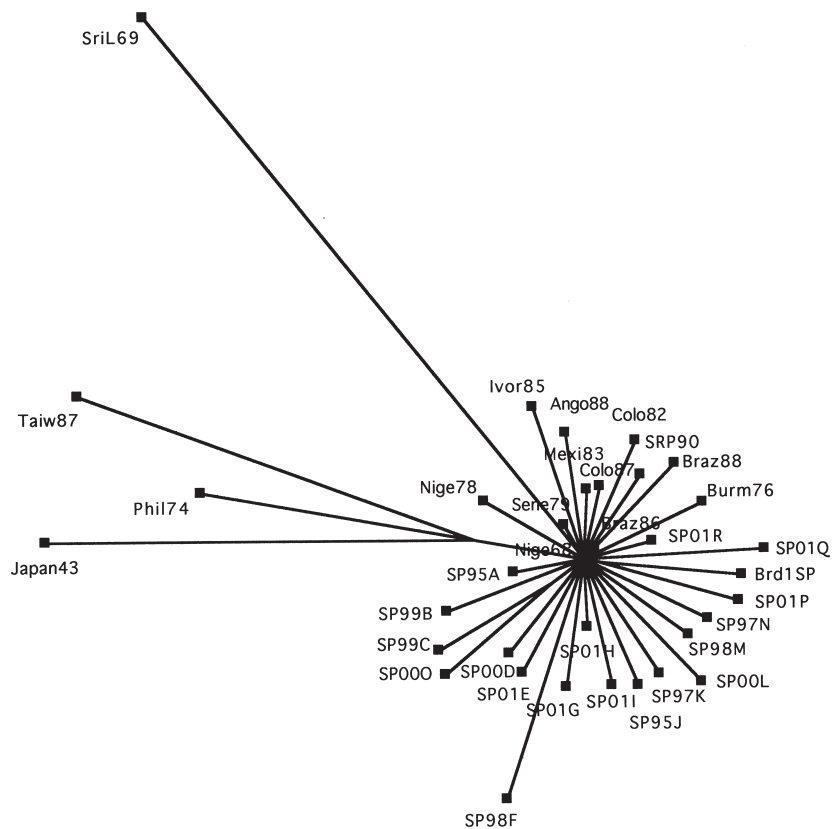

0.01

Fig. 2 - A graphical representation of the split-decomposable part of the evolutionary distance between DEN-1 sequence data generated using the distance matrix obtained under the TrNef $+\Gamma$ model (drawn to scale; force triangle inequalities). 
proportion. The posterior probabilities for most relationships among DEN-2 strains are higher than the corresponding ML bootstrap values. In fact, the posterior probabilities for 14 groups are higher than 0.65 (Fig. 3). Bayesian analyses recovered two major clusters: a cluster consisting of several Brazilian sequences, which were isolated from the State of São Paulo, Espírito Santo, Rio de Janeiro, Bahia and Rio Grande do Norte, and a cluster leading to four Brazilian strains, two isolated from Rio de Janeiro and both BR90_1 and BR90_2, and sequences representing genotypes II and III. The posterior probability for the split leading to the former cluster is 0.69 and for the latter cluster is 0.81 . Also, posterior probability for the group leading to Jamaica81 and both BR90_1 and BR90_2 sequences is 1.0 (Fig. 3). The split decomposition analysis reveals that conflicting relationships exist among DEN-2 sequences (Fig. 4). It also shows three main clusters, however, none of them represent previously defined genotypes of the virus. The first cluster consists of sequences of five Asian countries; however relation between these sequences is ambiguous. The second cluster consists of two Brazilian sequences (BR90_1 and BR90_2), Jamaica81 and Viet87, suggesting that they are of the same virus genotype. A third group is composed of sequences, which have been circulating in several regions in Brazil. The network shows ambiguities among these sequences but

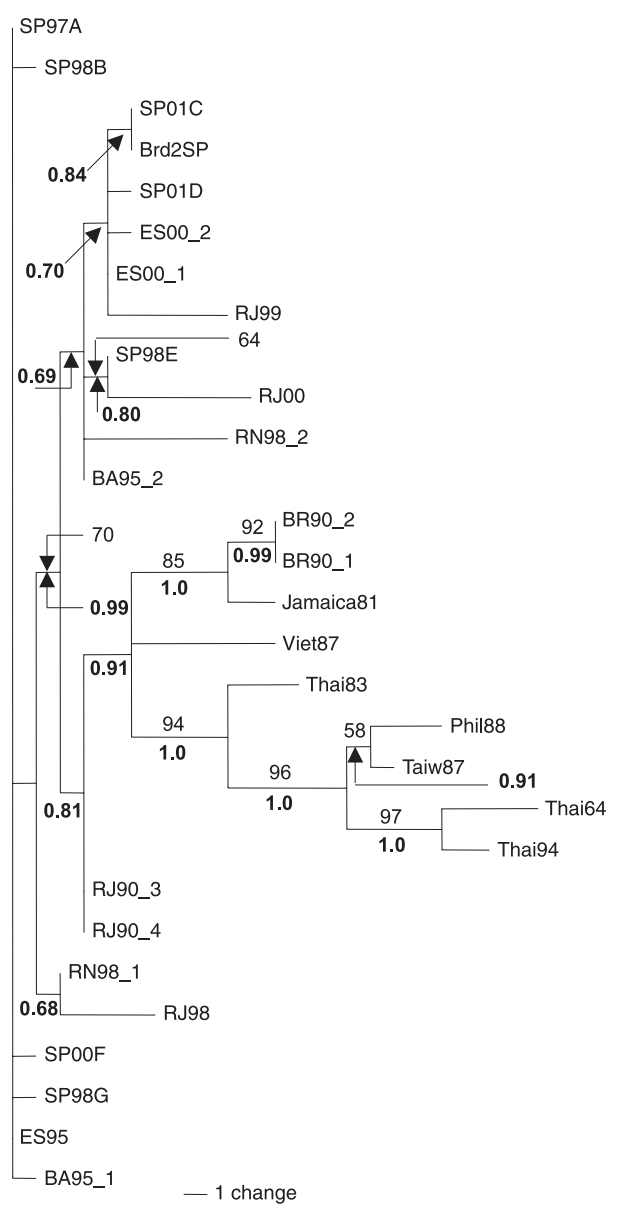

Fig. 3 - The single tree identified by maximum likelihood analysis of the E/NS1 junction region for DEN-2 data under the K80 + SS model of nucleotide substitution. Numbers above branches indicate ML bootstrap proportions obtained under the K80 + SS model, and numbers below branches indicate posterior probabilities obtained under the GTR + SS model. suggests that they belong to different subtypes of genotype III (Fig. 4). Excluding Phil88, Thai94, Thai83, Thai64 and Taiw87 from the split decomposition analysis, four subgroups were identified, a subgroup composed of Jamaica81, Viet87 and four Brazilian strains, which can be assigned to genotype III (not shown). The remaining Brazilian sequences cluster into three subgroups, which probably belong to different subtypes of genotype III and may be of different origin. The network graph shows ambiguities between all four subgroups (not shown).

\section{DISCUSSION}

According to the Brazilian Ministry of Health data, almost $70 \%$ of notified cases of dengue infection are concentrated in urban areas of municipalities with more than 50,000 inhabitants, which are undergoing to economic development. Commercial exchange among urban areas is considered to be responsible for Ae. aegypti dispersion and for the spread of dengue virus infection throughout Brazilian municipalities.

Dengue epidemics in the State of São Paulo, which is the most economically developed state in Brazil, and considered the main point for converging and dispersing national and international goods and people, have increased dramatically in recent years. Consequently, monitoring genetic changes in circulating or introduced viruses may be

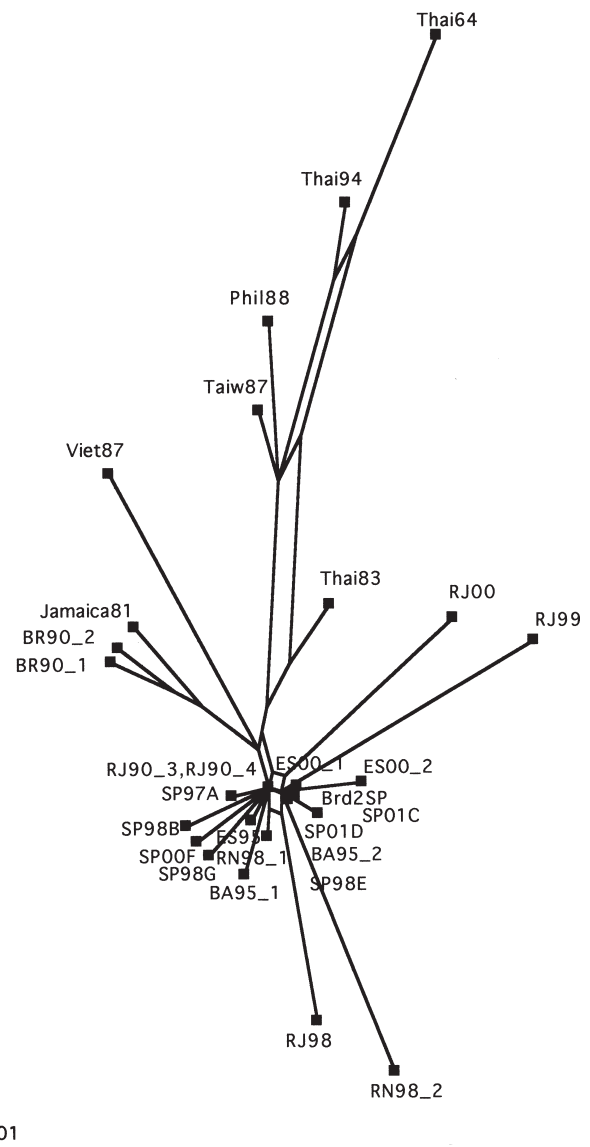

Fig. 4 - A graphical representation of the split-decomposable part of the evolutionary distance between DEN-2 sequence data generated using the distance matrix obtained under the GTR $+\Gamma$ model (drawn to scale; force triangle inequalities). 


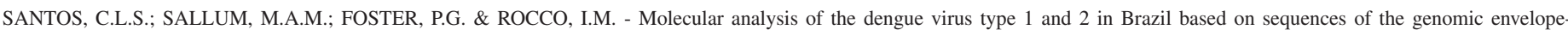
nonstructural protein 1 junction region. Rev. Inst. Med. trop. S. Paulo, 46(3):145-152, 2004.

useful to understand emergence of hyperendemicity associated with epidemics in an area ${ }^{12}$. In the present study, genetic diversity of several DEN-1 and DEN-2 isolates from autochthonous cases in Brazil was analyzed. The analysis involved the sequencing of a fragment of 240 base pairs of the E/NS1 gene junction of dengue virus. Although representing about two percent of the total dengue virus genome, E/ NS1 region was used to generate evolutionary information, which may be useful for molecular epidemiologic studies ${ }^{24,25}$. Nineteen DEN-1 and seven DEN-2 sequence variants were identified among 84 DEN-1 and 22 DEN-2 isolates. There were no significant differences in the distribution of these variants in either endemic areas or recent regions of dengue virus transmission. Variant A of DEN-1, for example, comprises the most fully dispersed one, which were isolated in Araçatuba (1995, 1996), São José do Rio Preto (1995, 1996, 1999, 2000), Ribeirão Preto (1990, 1995, 1996, 1999, 2000), Santos (1997, 1998, 2001), Campinas (1998, 2000), Barueri (2001) and during the first epidemic in São Paulo City in 2001. Furthermore, pairwise comparisons of variant SP95A and the sequence of a strain isolated in the State of Rio de Janeiro in 1990 considered the reference for DEN-1 epidemic in South America ${ }^{5,38}$ reveal $100 \%$ nucleotide identity. Sequences variants SP01P(DEN-1) and SP01C (DEN-2) are identical to Brd1SP and Brd2SP isolated from a patient with concurrent dengue infection ${ }^{29}$.

Sequence data were also used to examine phylogenetic relationships among sequences of dengue virus type 1 and type 2, isolated mainly from the State of São Paulo but also from different regions of Brazil and of the world. Although we have employed several sequences, which were also used in RICO-HESSE' ${ }^{24}$ study, phylogenetic relationships generated from the analyses performed for this study differ from those proposed genetic groups. Differences in the results may be partially attributable to the different methods of analysis employed in both studies, and also because DEN-1 and DEN-2 sequence data are not identical. GONÇALVEZ et al. $^{8}$ examined genetic diversity and phylogenetic relationships among 44 strains of DEN-1 from different regions of the world. They suggested the existence of five genotypes, with a single genotype circulating in the Americas associated with both DF and DHF/ DSS. Similarly, AVILÉS et al. ${ }^{1}$ indicated that a single genotype of DEN1 circulated in Argentina and Paraguay during epidemics in 2000. The results of all the analyses carried out for the present study indicate that different subtypes of a single genotype of DEN-1 virus are co-circulating in Brazil. Also, the network diagram generated when Burm76, Ango88, Ivor85, Sene69, Nige68, SriL69, Nige78, Taiw87, Phil74 and Japan43 were excluded, suggest that the genotype that is circulating in Brazil is closely related to Colo87, Colo82 and Mexi83 of genotype I of RICO$\mathrm{HESSE}^{24}$. Additionally, based on the results of all the analyses performed for the present study, it is reasonable to suppose that divergence among DEN-1 serotypes isolated from different regions of the world is not strong, corroborating the results of GONÇALVEZ et al. ${ }^{8}$ who estimated that divergence among the DEN-1 epidemic genotypes occurred approximately 100 years ago.

Previous studies have shown that DEN-2 strains, which are circulating in Brazil belong to genotype III within RICO-HESSE's classification ${ }^{21,25}$. In the present study, we have confirmed that BR90_1 and BR90_2 strains belong to genotype III. In addition, the results of both phylogenetic and split decomposition analyses indicate that the remaining strains isolated in several regions in Brazil are closely related and belong to distinct subtypes of the genotype III. However, relationship among them is ambiguous.
Finally, the results of the ML and Bayesian analysis are consistent with the conclusion that the E/NS1 gene region consisting of 240 base pairs does not contain enough information for recovering phylogenetic relationships within DEN-1 and DEN-2 sequences used for the present study. In addition, the results suggest that divergences among DEN-1 and DEN-2 sequences are very low and may have occurred too recently $8,15,37$ to be tracked by information in the E/NS1 data. The low genetic distance separating all the sequences seems to support this conclusion. In addition, it is also important to take into consideration that the maximum likelihood and Bayesian methods for phylogenetic inference assume that evolution is hierarchical. However, in virus genome, recombination, reassortment and horizontal transfer occur frequently. Regarding to dengue virus, recombination event is stressed since there has been increasing evidence for its occurrence in natural virus population ${ }^{35,36,39}$. Consequently, all standard methods for phylogenetic reconstruction, which assumes that evolution is a tree-like process, may recover incorrect topologies and poor resolution when used to analyze virus genome sequence data ${ }^{6,20}$.

\section{RESUMO}

\section{Análise molecular dos vírus dengue tipo 1 e 2 no Brasil, baseada nas seqüências da região da junção dos genes do envelope e da proteína não estrutural 1}

Foram determinadas as sequiências nucleotídicas da junção dos genes do envelope e da proteína não estrutural 1 (E/NS1) de 84 cepas de DEN1 e 22 cepas de DEN-2 do Brasil. A maioria dessas cepas foi isolada no período de 1995-2001, em regiões endêmicas e de transmissão recente no Estado de São Paulo. Sequiências da junção E/NS1 de DEN-1 e DEN2 de outras regiões geográficas brasileiras e mundiais, obtidas do GenBank, foram também utilizadas neste estudo. As análises foram efetuadas utilizando-se as técnicas de Verossimilhança Máxima e Bayesiana de inferência filogenética. Os resultados das análises das sequiências de DEN-1 e DEN-2 são ambíguos e o suporte para a maioria dos grupos é baixo, sugerindo que a região E/NS1 não é filogeneticamente informativa. O gráfico gerado na análise de decomposição dos grupos de DEN-1 não mostrou evidências de agrupamento das seqüências de acordo com os países, as regiões ou clados. No entanto, para DEN-2 evidenciou a existência de ambigüidades entre as seqüências, sugerindo que as brasileiras pertencem a subtipos distintos do genotipo III.

\section{ACKNOWLEDGMENTS}

Secretaria de Estado da Saúde do Estado de São Paulo and Fundação de Amparo à Pesquisa do Estado de São Paulo (FAPESP) Grant 1999/ 00558-2 for financial support. To M.A.A. Bastos for laboratory assistance, and Tiyo Sakurai and Gizelda Katz for suggestions and providing helpful comments to improve the paper. MAMS was supported by grant from FAPESP, São Paulo, Brasil. (Grant nº 99/10517-1).

\section{REFERENCES}

1. AVILÉS, G.; ROWE, J.; MEISSNER, J. et al. - Phylogenetic relationships of dengue-1 viruses from Argentina and Paraguay. Arch. Virol., 147: 2075-2087, 2002.

2. BANDELT, H.-J. \& DRESS, A. W. M. - Split decomposition: a new and useful approach to phylogenetic analysis of distance data. Molec. Phylogenet. Evol., 1: 242-252, 1992. 


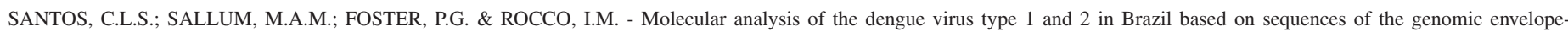
nonstructural protein 1 junction region. Rev. Inst. Med. trop. S. Paulo, 46(3):145-152, 2004.

3. CHOMCZYNSKI, P. \& SACCHI, N. - Single step method of RNA isolation by acid guanidinium thiocyanate-phenol-chloroform extraction. Analyt. Biochem., 162: 156159, 1987.

4. CHUNGUE, E.; CASSAR, O.; DROUET, M.T. et al. - Molecular epidemiology of dengue -1 and dengue-4 viruses. J. gen. Virol., 76: 1877-1884, 1995.

5. DESPRÈZ, P.; FRENKIEL, M.P. \& DEUBEL, V. - Differences between cell membrane fusion activities of two dengue type 1 isolates reflect modifications of viral structure. Virology, 196: 209-219, 1993

6. DOPAZO, J.; DRESS, A. \& HAESELER, A. VON - Split decomposition: a technique to analyze viral evolution. Proc. nat. Acad. Sci. (Wash.), 90: 10320-10324, 1993

7. FIGUEIREDO, L.T.M. - History, present and future of dengue fever in Brazil. In : TRAVASSOS DA ROSA, A.P.A.; VASCONCELOS, P.F.C. \& TRAVASSOS DA ROSA, J.F.S., ed. An overview of arbovirology in Brazil and neighbouring countries. Belém, Instituto Evandro Chagas, 1998. p. 155-163.

8. GONÇALVEZ, A.P.; ESCALANTE, A.A.; PUJOL, F.H. et al. - Diversity and evolution of the envelope gene of dengue virus type 1. Virology, 303: 110-119, 2002

9. GUBLER, D. J.; REED, D.; ROSEN, L. \& HITCHOCK Jr., J.R. - Epidemiologic, clinical, and virologic observations on dengue in the Kingdom of Tonga. Amer. J. trop. Med. Hyg., 27: 581-589, 1978.

10. GUBLER, D.J. - The global pandemic of dengue/dengue haemorrhagic fever: current status and prospects for the future. Ann. Acad. Med. Singapore, 27: 227-234, 1998a.

11. GUBLER, D.J. - Dengue and dengue hemorrhagic fever. Clin. Microbiol. Rev., 11: 480-496, 1998 b.

12. GUBLER, D.J. - The global emergence/resurgence of arboviral diseases as public health problems. Arch. med. Res., 33: 330-342, 2002.

13. GUBLER, D.J.; KUNO, G.; SATHER, G.E.; VELEZ, M. \& OLIVER, A. - Mosquito cell cultures and specific monoclonal antibodies in surveillance for dengue viruses. Amer. J. trop. Med. Hyg., 33: 158-165, 1984

14. HALSTEAD, S.B. - Pathogenesis of dengue: challenges to molecular biology. Science, 239: 476-481, 1988.

15. HOLMES, E.C. \& TWIDDY, S.S. - The origin, emergence and evolutionary genetics of dengue virus. Infect. Genet. Evol., 3: 19-28, 2003.

16. HUELSENBECK, J.P. \& RONQUIST, F. - MrBayes: Bayesian inference of phylogeny. Rochester, Department of Biology, University of Rochester, 2002. (Distributed by the author).

17. HUSON, D.H. - SplitsTree: analyzing and visualizing evolutionary data. Bioinformatics, 14: $68-73,1998$.

18. KIMURA, M. - A simple method for estimating evolutionary rates of base substitutions through comparative studies of nucleotide sequences. J. molec. Evol., 16: 111-120, 1980 .

19. LEWIS, J.G.; CHANG, G.J.; LANCIOTTI, R.S. et al. - Phylogenetic relationships of dengue-2 viruses. Virology, 197: 216-224, 1993

20. McCORMACK, G.P. \& CLEWLEY, J.P. - The application of molecular phylogenetics to the analysis of viral genome diversity and evolution. Rev. med. Virol., 12: 221-238, 2002 .

21. MIAGOSTOVICH, M.P.; SEQUEIRA, P.C.; DOS SANTOS, F.B. et al. - Molecular typing of dengue virus type 2 in Brazil. Rev. Inst. Med. trop. S. Paulo, 45: 17-21, 2003.
22. NOGUEIRA, R.M.R.; MIAGOSTOVICH, M.P.; FILIPPIS, A.M.B. et al. - Dengue virus type 3 in Rio de Janeiro, Brazil. Mem. Inst. Oswaldo Cruz, 96: 925-926, 2001

23. POSADA, D. \& CRANDALL, K.A. - Modeltest: testing the model of DNA substitution. Bioinformatics, 14: 817-818, 1998.

24. RICO-HESSE, R. - Molecular evolution and distribution of dengue viruses type 1 and 2 in nature. Virology, 174: 479-493, 1990.

25. RICO-HESSE, R.; HARRISON, L.M.; SALAS, R.A. et al. - Origins of dengue type 2 viruses associated with increased pathogenicity in the Americas. Virology, 230: 244251, 1997.

26. ROCCO, I.M.; KAVAKAMA, B.B. \& SANTOS, C.L.S. - First isolation of dengue 3 in Brazil from an imported case. Rev. Inst. Med. trop. S. Paulo, 43: 55-57, 2001.

27. RODRIGUEZ, F.; OLIVER, J.L.; MARIN, A. \& MADINA, J.R. - The general stochastic model of nucleotide substitution. J. theor. Biol., 142: 485-501, 1990.

28. ROSEN, L. - The Emperor's New Clothes revisited, or reflections on the pathogenesis of dengue hemorrhagic fever. Amer. J. trop. Med. Hyg., 26: 337-343, 1977.

29. SANTOS, C.L.S.; BASTOS, M.A.A.; SALLUM, M.A.M. \& ROCCO, I.M. - Molecular characterization of dengue viruses type 1 and 2 isolated from a concurrent human infection. Rev. Inst. Med. trop. S. Paulo, 45: 11-16, 2003.

30. SCOTT, R.M. - Shock syndrome in primary dengue infections. Amer. J. trop. Med. Hyg., 25: 866-874, 1976

31. SWOFFORD, D.L. - PAUP*. Phylogenetic Analysis Using Parsimony (*and Other Methods), Version 4. Sunderland, Sinauer Associates, 2002.

32. SWOFFORD, D.L.; OLSEN, G.J.; WADELL, P.J. \& HILLIS, D.M. - Phylogenetic inference. In: HILLIS, D.M.; MORITZ, C. \& MABLE, B.K., ed. Molecular systematics. 2. ed. Sunderland, Sinauer Associates, 1996. p. 407-514.

33. TAMURA, K. \& NEI, M. - Estimation of the number of nucleotide substitutions in the control region of mitochondrial DNA in humans and chimpanzees. Molec. Biol. Evol., 10: 512-526, 1993.

34. THOMPSON, J.D.; GIBSON, T.J.; PLEWNIAK, F. et al. - The CLUSTAL X windows interface: flexible strategies for multiple sequence alignment aided by quality tools. Nucleic Acids Res., 24: 4876-4882, 1997.

35. TOLOU, H.J.; COUSSINIER-PARIS, P. DURAND, J.P et al. - Evidence for recombination in natural populations of dengue virus type 1 based on the analysis of complete genome sequences. J. gen. Virol., 82: 1283-1290, 2001.

36. TWIDDY, S.S. \& HOLMES, E.C. - The extent of homologous recombination in members of the genus Flavivirus. J. gen. Virol., 84: 429-440, 2003.

37. TWIDDY, S.S.; HOLMES, E.C. \& RAMBAUT, A. - Inferring the rate and time-scale of dengue virus evolution. Mol. Biol. Evol., 20: 122-129, 2003.

38. WANG, E.; NI, H.; XU, R. et al. - Evolutionary relationships of endemic/epidemic and sylvatic dengue viruses. J. Virol., 74: 3227-3234, 2000.

39. WOROBEY, M.; RAMBAUT, A. \& HOLMES, E.C. - Widespread intra-sorotype recombination in natural populations of dengue virus. Proc. nat. Acad. Sci. (Wash.), 96: 7352-7357, 1999

40. ZHARKIKH, A. - Estimation of evolutionary distances between nucleotide sequences J. Molec. Evol., 39: 315-329, 1994

Received: 30 September 2003

Accepted: 7 june 2004 